\title{
Maternal probiotic milk intake during pregnancy and breastfeeding complications in the Norwegian Mother and Child Cohort Study
}

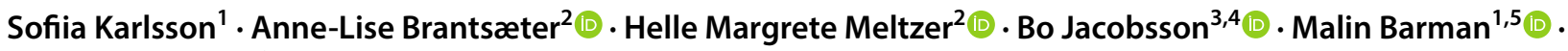 \\ Verena Sengpiel ${ }^{1,3}$
}

Received: 18 February 2019 / Accepted: 27 July 2019 / Published online: 10 September 2019

(c) The Author(s) 2019

\begin{abstract}
Purpose During the time of breastfeeding, a third of all women contract (or: fall ill in) mastitis - the leading cause of precocious weaning. Recent studies indicate that probiotics intake may prevent mastitis by altering the breast's bacterial flora. The aim of this study was to examine whether probiotic milk intake during pregnancy is associated with less breastfeeding complications and longer breastfeeding duration.

Methods This study included 57,134 women, with live singleton term births, participating in the Norwegian Mother and Child Cohort Study. Probiotic milk intake during the first half of pregnancy was self-reported in a validated food frequency questionnaire at gestational week 22. At 6 month postpartum, women reported complications, including mastitis, and duration and exclusivity of breastfeeding. The association between probiotic milk intake and breastfeeding complications and duration was studied by adjusted logistic regression models.

Results Probiotic milk intake was associated with increased risk for mastitis [adjusted odds ratio (aOR) 1.09, 95\% confidence interval (CI) 1.02-1.16] and for any breastfeeding problems during the first month (aOR 1.19, 95\% CI 1.10-1.21). However, cessation of predominant (aOR $0.95,95 \% \mathrm{CI} 0.91-0.96$ ) or any (aOR $0.79,95 \% \mathrm{CI} 0.75-0.84$ ) breastfeeding earlier than at 4 months was less frequent in probiotic milk consumers than in non-consumers.

Conclusions Even though probiotic milk intake during the first half of pregnancy was statistically associated with increased risk for breastfeeding complications, including mastitis, the association is probably not causal. Probiotics intake was namely associated with longer breastfeeding duration and there was indication of socioeconomic confounding. Further studies, i.e., large randomized-controlled trials, are needed to understand the association between probiotic intake and breastfeeding complications.
\end{abstract}

Keywords Probiotics · Probiotic milk intake · Cessation of breastfeeding · Mastitis · Breastfeeding complications $\cdot$ The Norwegian Mother and Child Cohort Study

Electronic supplementary material The online version of this article (https://doi.org/10.1007/s00394-019-02072-8) contains supplementary material, which is available to authorized users.

Verena Sengpiel

verena.sengpiel@obgyn.gu.se

1 Department of Obstetrics and Gynaecology, Sahlgrenska University Hospital, Gothenburg, Sweden

2 Division of Infection Control, Environment and Health, Norwegian Institute of Public Health, Oslo, Norway

3 Department of Obstetrics and Gynaecology, Institute of Clinical Sciences, University of Gothenburg, Gothenburg, Sweden
4 Department of Genetics and Bioinformatics, Domain of Health Data and Digitalisation, Institute of Public Health, Oslo, Norway

5 Department of Biology and Biological Engineering, Food and Nutrition Science, Chalmers University of Technology, Gothenburg, Sweden 


\section{Background}

Lactational mastitis is defined as an inflammatory process of the mammary gland, characterized by pain in the breast in conjunction with flu-like symptoms during breastfeeding. The World Health Organization (WHO) review on lactational mastitis reports an incidence ranging between $2.6 \%$ and $33 \%$ [1]. While WHO recommends 6 months of exclusive breastfeeding, lactational mastitis is the leading cause of unplanned precocious weaning [1-3]. It causes substantial suffering for the mother and often disturbs the sensitive period of bonding between mother and newborn.

While mastitis previously was considered the consequence of a bacterial infection, new evidence suggests that breast health is instead determined by a balance between different microbiota in the breast tissue, as well as by the state of the host's immune system $[4,5]$. While antibiotics have been the traditional treatment approach, four recent randomized-controlled trials (RCT) from Spain presented promising results with treatment ( $n=352$ [6], $n=108$ [7]) or prophylactic intake ( $n=108$ [8], $n=625$ [9]) of certain probiotic strains namely Lactobacillus (L.) salivarius, L. gasseri, and/or L. fermentum.

Several mechanisms for improvement of breast flora by probiotics have been described, e.g., local competitive exclusion [10], production of antimicrobials [11], normalization of breast tissue permeability [12], and increase of immunoglobulin A in breast milk, which may limit the bacteria's ability to damage mammary epithelium [13].

Today, probiotics are part of many milk products commonly purchased and widely consumed by the general population, including pregnant women. Our group has previously reported that free-market probiotic milk intake during pregnancy containing Lactobacillus acidophilus La-5 (La-5), Bifidobacterium lactis Bb12 (Bb12), and Lactobacillus rhamnosus GG (LGG) is associated with decreased risk for preterm delivery [14] and preeclampsia $[15,16]$. To our knowledge, no previous studies have investigated the association between freemarket probiotic milk intake and breastfeeding complications and duration. The Norwegian Mother and Child Cohort Study $(\mathrm{MoBa})$ has compiled detailed information on maternal probiotic milk intake during pregnancy, comprehensive information on breastfeeding, as well as general information on health and lifestyle [17]. It is thus a unique source for studying a possible preventive effect of probiotic milk intake during pregnancy on breastfeeding complications and duration in a populationbased cohort.

\section{Objective}

We hypothesized that free-market probiotic milk intake during pregnancy prevents breastfeeding complications and thus promotes longer breastfeeding by stabilizing healthy breast flora. The aim of this study was to evaluate whether intake of probiotic milk products during pregnancy is associated with less breastfeeding complications, i.e., mastitis, medication for mastitis, sore nipples or other problems, or associated with longer breastfeeding duration (no cessation of any or predominant breastfeeding before 4 months).

\section{Materials and methods}

\section{Study population}

The MoBa is a prospective, population-based pregnancy cohort study conducted by the Norwegian Institute of Public Health [17]. Participants were recruited from all over Norway from 1999 to 2008 , and $41 \%$ of invited women consented to participate. Follow-up is conducted by questionnaires at regular intervals and by linkage to pregnancy and birth records in the Norwegian Medical Birth Register (NMBR) [18]. All questionnaires $(Q)$ are available on the website of the Norwegian Institute of Public Health [19].

This study is based on version 10 of the quality-assured data files released for research in 2017.

\section{Inclusion and exclusion criteria}

Out of 114,240 births registered in MoBa, all singleton pregnancies with live births after gestational week $37+0$ were included in the study. Women had to have filled in questionnaires Q1 on general health and lifestyle, Q2 on dietary habits during pregnancy, and Q4 on follow-up 6 month postpartum. As a quality measure of Q2, a food frequency questionnaire (FFQ), only women reporting an energy intake between 4.5 and 20 megajoules (MJ) daily were included. Mothers with reported autoimmune disease or cancer were excluded, as were babies born with serious malformations. Only the first pregnancy enrolled in MoBa was included in the analyses, to avoid repeated assessments of the same mother. After exclusion of women who did not initiate breastfeeding, 57,134 mother-baby pairs remained (see Fig. 1).

\section{Exposure}

Maternal probiotic milk intake during the first half of pregnancy was self-reported in the MoBa FFQ, a semi-quantitative questionnaire designed to record dietary habits. FoodCalc [20] and the Norwegian Food Composition Table [21] were used to calculate food and nutrient intakes. A validation study of the FFQ showed that, relative to a dietary reference method and several biological markers, the MoBa FFQ produces a realistic estimate of habitual intake and is a 
Fig. 1 Flowchart showing selection of study participants from the Norwegian Mother and Child Cohort Study (MoBa)

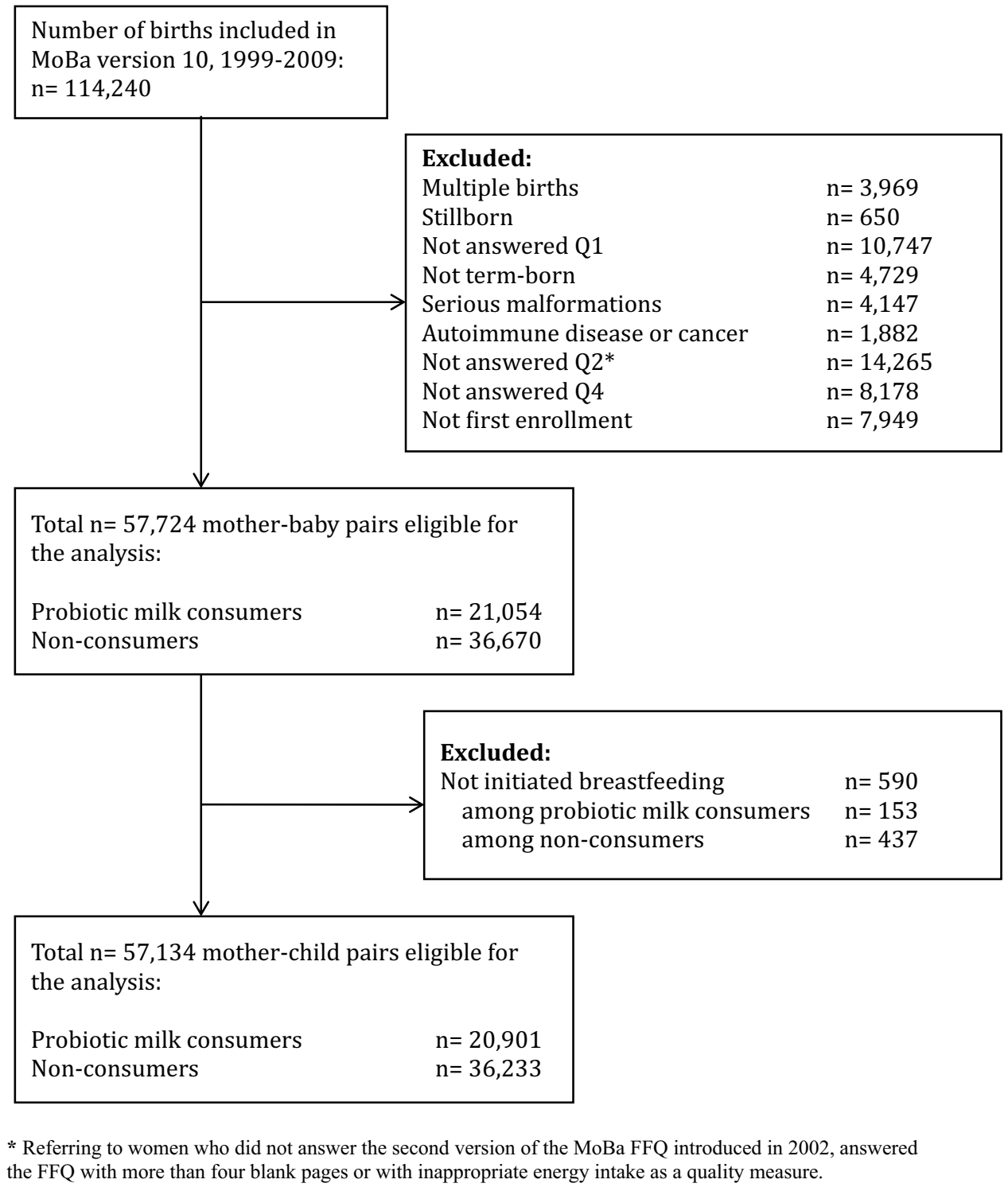

valid tool for ranking pregnant women according to high and low intakes of energy, nutrients, and food [22].

The FFQ asked specifically about intake frequency of two probiotics-containing dairy products produced by Tine SA, Oslo, Norway (Product A: Biola ${ }^{\circledR}$, containing La-5, Bb12 and LGG; and product B: Cultura ${ }^{\circledR}$, containing La-5 and $\mathrm{Bb} 12)$. Responses ranged from "never" to "8 or more times per day", with a total of 11 response alternatives. One glass was specified as $250 \mathrm{ml}$. The bacteria count in these beverages is indicated as a minimum of $2 \times 10^{8} \mathrm{CFU}$ of LGG and Bb12 and $2 \times 10^{7} \mathrm{CFU}$ of La-5 per $1 \mathrm{~mL}$ product $\mathrm{A}$ and a minimum of $2 \times 10^{8} \mathrm{CFU}$ of Bb12 and $2 \times 10^{7} \mathrm{CFU}$ of La- 5 per $1 \mathrm{~mL}$ product $\mathrm{B}$. These products were the only widely consumed probiotic products available on the Norwegian market at the time of the study. The MoBa FFQ included questions about the use of dietary supplements and an open text field for reporting supplements other than those listed.
Very few women (fewer than $0.5 \%$ ) reported consumption of probiotic supplements, and intake of probiotics from supplements was thus not considered in this study.

Probiotic milk intake from both sources combined was studied as a dichotomous variable (yes/no) as well as in tertiles of probiotics intake (low, medium, and high).

\section{Outcome}

In Q4, administered 6 month postpartum, women were asked whether they had consulted a doctor, midwife, or health visitor during the first month after delivery for breast-related problems, specified as "mastitis", "sore nipples", or "breastfeeding problems", and whether they had received "medication for mastitis". In addition to these four variables, a combined variable, "any breastfeeding problems", was created. 
Furthermore, mothers reported the specifics of their babies' nutrition, both during the first week of life, choosing between breast milk, sugar water, water, and different types of formula, and then monthly, choosing between breast milk and different types of formula. Two breastfeeding variables were created based on the WHO definitions [23]: "cessation of predominant breastfeeding before 4 months" and "cessation of any breastfeeding before 4 months". "Exclusive breastfeeding" could only be reported for the first week of life, as the questionnaires did not specifically ask about ingestion of water, water-based drinks, and fruit juices later on. "Predominant breastfeeding" refers to infants either given only breast milk (exclusive breastfeeding) or breast milk and water-based drinks, but infants should not be fed with solid food, nonhuman milk or formula. This group thus includes those who were breastfed exclusively during their first week of life. "Any breastfeeding" refers to infants either given only breast milk (exclusive breastfeeding), predominantly breastfed (see above) or partially breastfed, i.e., given solid food, formula, or nonhuman milk in addition to breast milk [23].

\section{Confounders}

Confounders were selected a priori. Maternal age was registered in the NMBR and used as a continuous variable. The following variables were self-reported in Q1: maternal pre-pregnancy BMI was calculated based on reported height and pre-pregnancy weight and used as a categorical variable $\left(<18.5,18.5-24.9,25-29.9,>30 \mathrm{~kg} / \mathrm{m}^{2}\right)$. Maternal education was categorized as $<13,13-16, \geq 16$ years. Family income was recorded as neither, one or both partners earning > 300,000 Norwegian Crowns (NOK)/year. Maternal smoking categories during pregnancy were never, occasionally, and daily.

Based on the FFQ, daily fibre and energy intake were considered as continuous variables, while non-probiotic yoghurt and milk consumption were calculated as described above for probiotic milk intake.

\section{Statistics}

All analyses were performed using IBM ${ }^{\circledR}$ SPSS ${ }^{\circledR}$ Statistics version 25. Maternal characteristics, related to probiotic milk consumption, were analysed using Pearson's chi-square test or the two-sided Fisher's exact test. The Kruskal-Wallis test was used to study whether there was a statistical difference between the amounts of probiotic milk intake in the different maternal characteristic categories.

The associations between being a probiotic milk consumer and breastfeeding complications and duration were studied by logistic regression analysis, unadjusted and adjusted for the confounders described above. Missing data were given a category of their own.
Sensitivity analyses were performed for the association between education and reported breastfeeding complications and duration, as well as between reported breastfeeding complications and breastfeeding duration.

\section{Results}

\section{Probiotic milk intake in the study population}

In our study population, 20,901 (36.6\%) women were probiotic milk consumers. The median daily intake (interquartile range) among consumers was $54 \mathrm{ml} /$ day (IQR 22-179).

Probiotic milk consumers had lower parity, although they were older. They had higher educational levels and income as well as more health-conscious behaviour, with higher fibre intake and less smoking than non-consumers (see Table 1).

\section{Breastfeeding complications and duration}

During the first month after delivery, a total of 4675 (8\%) women in the study population contacted healthcare services for mastitis and 3127 of these (6\% of the total study population) received medication for the mastitis. Sore nipples were reported by 3595 women (6\%) and $3665(6 \%)$ reported other breastfeeding problems. In total, 8788 women $(15 \%)$ contacted healthcare services for any breastfeeding problems during the first month after delivery. Of the study population, 22,235 women (39\%) ceased to predominantly breastfeed and 6567 women (11\%) stopped any breastfeeding before the baby reached the age of 4 months.

Probiotic milk intake was significantly associated with a higher incidence of breastfeeding complications (except for medication-treated mastitis), as well as a lower frequency of breastfeeding cessation before 4 months. Odds ratios (OR) became less pronounced after adjustment, but results remained significant (except for medication-treated mastitis, see Table 2).

However, there was no dose-response association between amount of probiotic milk intake either with breastfeeding complications or duration (see Supplemental Table 1).

Sensitivity analyses were performed to better understand the contradicting results of probiotic milk consumers having a higher incidence of breastfeeding complications, while also breastfeeding longer. First, the known association between breastfeeding complications and earlier cessation of breastfeeding was confirmed in this study population (see Table 3). Associations remained the same when studying the subgroups of probiotic milk consumers and non-consumers separately (data not shown). 
Table 1 Probiotic milk intake according to maternal characteristics, $n=57,134$ women

\begin{tabular}{|c|c|c|c|c|c|}
\hline & \multicolumn{2}{|c|}{ Probiotic milk consumption } & \multirow[t]{2}{*}{$p$ value $^{1}$} & \multirow{2}{*}{$\begin{array}{l}\text { Mean (SD) daily probiotics intake among } \\
\text { probiotics consumers, ml/day }\end{array}$} & \multirow[t]{2}{*}{$p$ value $^{1}$} \\
\hline & No, number (\%) & Yes, number $(\%)$ & & & \\
\hline All & $36,233(63.4)$ & $20,901(36.6)$ & & $123(176)$ & \\
\hline \multicolumn{6}{|c|}{ Maternal age, years } \\
\hline$<25$ & $4190(11.6)$ & $1830(8.8)$ & \multirow[t]{4}{*}{$<0.001$} & $111(168)$ & \multirow[t]{4}{*}{$<0.001$} \\
\hline $25-29$ & $12,278(33.9)$ & $7193(34.4)$ & & $122(174)$ & \\
\hline $30-34$ & $15,478(42.7)$ & $9217(44.1)$ & & $123(175)$ & \\
\hline$\geq 35$ & $4287(11.8)$ & $2661(12.7)$ & & $135(185)$ & \\
\hline \multicolumn{6}{|c|}{ Pre-pregnancy BMI, kg/m² } \\
\hline$<18.5$ & $1025(2.8)$ & $582(2.8)$ & \multirow[t]{5}{*}{$<0.001$} & $129(182)$ & \multirow[t]{5}{*}{0.01} \\
\hline $18.5-24.9$ & $22,526(62.2)$ & $14,572(69.7)$ & & $124(174)$ & \\
\hline $25-29.9$ & $8070(22.3)$ & $3961(19.0)$ & & $122(178)$ & \\
\hline$\geq 30$ & $3686(10.2)$ & $1339(6.4)$ & & $113(171)$ & \\
\hline Missing & $926(2.6)$ & $447(2.1)$ & & $128(204)$ & \\
\hline \multicolumn{6}{|l|}{ Parity } \\
\hline 0 & $17,061(47.1)$ & $11,987(57.4)$ & \multirow[t]{5}{*}{$<0.001$} & $126(178)$ & \multirow[t]{5}{*}{$<0.001$} \\
\hline 1 & $12,468(34.4)$ & $5957(28.5)$ & & $117(171)$ & \\
\hline 2 & $5398(14.9)$ & $2436(11.7)$ & & $119(173)$ & \\
\hline$\geq 3$ & $1278(3.5)$ & $506(2.4)$ & & $135(196)$ & \\
\hline Missing & $28(0.1)$ & $15(0.1)$ & & $71(125)$ & \\
\hline \multicolumn{6}{|c|}{ Maternal education, years } \\
\hline$<13$ & $12,192(33.6)$ & $4555(21.8)$ & \multirow[t]{4}{*}{$<0.001$} & $128(186)$ & \multirow[t]{4}{*}{0.01} \\
\hline $13-16$ & $15,250(42.1)$ & $9146(43.8)$ & & $119(174)$ & \\
\hline$\geq 16$ & $8032(22.2)$ & $6840(32.7)$ & & $123(168)$ & \\
\hline Missing & $759(2.1)$ & $360(1.7)$ & & $144(226)$ & \\
\hline \multicolumn{6}{|c|}{ Family income $>300,000 \mathrm{NOK}$} \\
\hline Neither partner & $10,678(29.5)$ & $4756(22.8)$ & \multirow[t]{4}{*}{$<0.001$} & $115(168)$ & \multirow[t]{4}{*}{$<0.001$} \\
\hline One partner & $15,308(42.2)$ & $8379(40.1)$ & & $123(172)$ & \\
\hline Both partners & $9287(25.6)$ & $7298(34.9)$ & & $127(181)$ & \\
\hline Missing & $960(2.6)$ & $468(2.2)$ & & $138(219)$ & \\
\hline \multicolumn{6}{|c|}{ Smoking in pregnancy } \\
\hline Never & $32,802(90.5)$ & $19,864(95.0)$ & \multirow[t]{4}{*}{$<0.001$} & $123(176)$ & \multirow[t]{4}{*}{0.002} \\
\hline Occasionally & $1025(2.8)$ & $401(1.9)$ & & $124(166)$ & \\
\hline Daily & $2193(6.1)$ & $540(2.6)$ & & $119(177)$ & \\
\hline Missing & $213(0.6)$ & $96(0.5)$ & & 109 (177) & \\
\hline \multicolumn{6}{|c|}{ Tertiles of daily energy intake } \\
\hline $1 \mathrm{st}$ & $12,987(35.8)$ & $6044(28.9)$ & $<0.001$ & 85 (107) & $<0.001$ \\
\hline 2nd & $11,948(33.0)$ & $7111(34.0)$ & & $112(144)$ & \\
\hline $3 \mathrm{rd}$ & $11,298(31.2)$ & $7746(37.1)$ & & $161(229)$ & \\
\hline Tertiles of daily fi & take & & & & \\
\hline $1 \mathrm{st}$ & $13,388(36.9)$ & $5607(26.8)$ & $<0.001$ & $96(146)$ & $<0.001$ \\
\hline 2nd & $12,068(33.3)$ & $7010(33.5)$ & & $117(168)$ & \\
\hline $3 \mathrm{rd}$ & $10,777(29.7)$ & $8281(39.6)$ & & $146(196)$ & \\
\hline Tertiles of daily $n$ & biotic milk intake & & & & \\
\hline $1 \mathrm{st}$ & $11,610(32.0)$ & $6695(32.0)$ & 0.29 & $130(187)$ & $<0.001$ \\
\hline 2 nd & $13,121(36.2)$ & $7453(35.7)$ & & $123(161)$ & \\
\hline $3 r d$ & $11,502(31.7)$ & 6753 (32.3) & & $115(179)$ & \\
\hline
\end{tabular}


Table 1 (continued)

\begin{tabular}{lll} 
Probiotic milk consumption & $p$ value $^{1}$ & $\begin{array}{l}\text { Mean (SD) daily probiotics intake among } \\
\text { probiotics consumers, ml/day }\end{array}$ \\
\hline No, number $(\%)$ & Yes, number $(\%)$
\end{tabular}

\begin{tabular}{|c|c|c|c|c|c|}
\hline \multicolumn{6}{|c|}{ Tertiles of daily non-probiotic yoghurt intake } \\
\hline $1 \mathrm{st}$ & $13,958(38.5)$ & $4967(23.8)$ & \multirow[t]{3}{*}{$<0.001$} & $120(175)$ & \multirow[t]{3}{*}{$<0.001$} \\
\hline 2nd & $11,389(31.4)$ & $8013(38.3)$ & & $105(157)$ & \\
\hline $3 \mathrm{rd}$ & $10,886(30.0)$ & $7921(37.9)$ & & $143(191)$ & \\
\hline \multicolumn{6}{|c|}{ Caesarean section } \\
\hline No & $31,497(86.9)$ & $18,255(87.3)$ & \multirow[t]{2}{*}{0.16} & $122(175)$ & \multirow[t]{2}{*}{0.10} \\
\hline Yes & $4736(13.1)$ & $2646(12.7)$ & & $130(181)$ & \\
\hline \multicolumn{6}{|c|}{ NICU admission } \\
\hline no & $31,948(88.2)$ & $18,134(86.8)$ & \multirow[t]{2}{*}{$<0.001$} & $123(174)$ & \multirow[t]{2}{*}{0.53} \\
\hline yes & $4285(11.8)$ & $2767(13.2)$ & & $122(185)$ & \\
\hline \multicolumn{6}{|c|}{ Baby SGA } \\
\hline No & $35,727(98.6)$ & $20,593(98.5)$ & \multirow[t]{2}{*}{0.46} & $123(175)$ & \multirow[t]{2}{*}{0.50} \\
\hline Yes & $506(1.4)$ & $308(1.5)$ & & $141(224)$ & \\
\hline \multicolumn{6}{|c|}{ Baby LGA } \\
\hline No & $34,772(96.0)$ & $20,234(96.8)$ & \multirow[t]{2}{*}{$<0.001$} & $123(176)$ & \multirow[t]{2}{*}{0.55} \\
\hline Yes & $1461(4.0)$ & $667(3.2)$ & & 120 (159) & \\
\hline
\end{tabular}

$I Q R$ interquartile range, SGA small for gestational age, according to Marsál, LGA large for gestational age, according to Marsál [24]

${ }^{1} p$ value according to Pearson's chi-square test or two-sided Fisher's exact test, as appropriate

${ }^{2} p$ value according to Kruskal-Wallis test

Table 2 Associations between probiotic milk intake and breastfeeding complications and breastfeeding duration, $n=57,134$ women

\begin{tabular}{|c|c|c|c|c|c|c|}
\hline & \multirow{2}{*}{$\begin{array}{l}\text { Among non-consumers } \\
\text { Number }(\%)\end{array}$} & \multirow{2}{*}{$\begin{array}{l}\text { Among probiotic } \\
\text { milk consumers } \\
\text { Number }(\%)\end{array}$} & \multicolumn{2}{|l|}{ Unadjusted } & \multicolumn{2}{|l|}{ Adjusted $^{\mathrm{a}}$} \\
\hline & & & $\mathrm{OR}(\mathrm{CI})$ & $p$ & $\mathrm{OR}(\mathrm{CI})$ & $p$ \\
\hline Mastitis & $2,818(7.8)$ & $1,857(8.9)$ & $1.16(1.09-1.23)$ & $<0.001$ & $1.09(1.02-1.16)$ & 0.01 \\
\hline Medication for mastitis & $1,892(5.2)$ & $1,235(5.9)$ & $1.14(1.06-1.23)$ & 0.001 & $1.07(1.00-1.15)$ & 0.09 \\
\hline Sore nipples & $2,029(5.6)$ & $1,566(7.5)$ & $1.37(1.28-1.46)$ & $<0.001$ & $1.22(1.14-1.31)$ & $<0.001$ \\
\hline Other breastfeeding problems & $2,053(5.7)$ & $1,612(7.7)$ & $1.39(1.30-1.49)$ & $<0.001$ & $1.22(1.13-1.30)$ & $<0.001$ \\
\hline Any breastfeeding problems & $5,154(14.2)$ & $3,634(17.4)$ & $1.27(1.21-1.33)$ & $<0.001$ & $1.19(1.10-1.21)$ & $<0.001$ \\
\hline $\begin{array}{l}\text { Cessation of predominant } \\
\text { breastfeeding before } 4 \text { months }\end{array}$ & $14,466(39.9)$ & $7,769(37.2)$ & $0.89(0.86-0.92)$ & $<0.001$ & $0.95(0.91-0.96)$ & 0.006 \\
\hline $\begin{array}{l}\text { Cessation of any breastfeeding } \\
\text { before } 4 \text { months }\end{array}$ & $4,758(13.1)$ & $1,809(8.7)$ & $0.63(0.59-0.66)$ & $<0.001$ & $0.79(0.75-0.84)$ & $<0.001$ \\
\hline
\end{tabular}

${ }^{a}$ Logistic regression adjusted for maternal age, maternal pre-pregnancy BMI, maternal education, family income, maternal smoking, fibre intake, energy intake, non-probiotic yoghurt consumption, and non-probiotic milk consumption

Second, higher maternal education was associated with higher incidence of reported breastfeeding complications during the first month after delivery, as well as with longer duration of breastfeeding (see Supplemental Table 2).

\section{Discussion}

In this population-based cohort study including 57,134 women, self-reported probiotic milk consumption during the first half of pregnancy was statistically associated with higher incidence of self-reported breastfeeding complications leading to healthcare consultations during the first month after delivery. Furthermore, self-reported probiotic milk consumption was associated with lower prevalence of breastfeeding cessation before the baby reached the age of 4 months.

The findings in this study do not support the hypothesis that general probiotic milk intake during pregnancy prevents future breastfeeding complications. However, results of different sensitivity analyses suggest that the association between probiotic milk intake and breastfeeding 
Table 3 Association between breastfeeding problems and cessation of predominant breastfeeding before 4 months, $n=57,134$ women

\begin{tabular}{|c|c|c|c|c|c|c|}
\hline & \multicolumn{2}{|c|}{$\begin{array}{l}\text { Predominant breast- } \\
\text { feeding before age } \\
4 \text { months (in \%) in } \\
\text { case of breastfeeding } \\
\text { complication }\end{array}$} & \multicolumn{2}{|l|}{ Unadjusted } & \multicolumn{2}{|l|}{ Adjusted $^{\mathrm{a}}$} \\
\hline & Not present & Present & $\begin{array}{l}\text { OR }(\mathrm{CI}) \text { for cessation of breast- } \\
\text { feeding in case of breastfeeding } \\
\text { complication }\end{array}$ & $p$ & $\begin{array}{l}\text { OR }(\mathrm{CI}) \text { for cessation of breast- } \\
\text { feeding in case of breastfeeding } \\
\text { complication }\end{array}$ & $p$ \\
\hline Mastitis & 61.8 & 53.3 & $1.41(1.33-1.50)$ & $<0.001$ & $1.47(1.38-1.57)$ & $<0.001$ \\
\hline Medication for mastitis & 61.6 & 52.8 & $1.43(1.33-1.54)$ & $<0.001$ & $1.50(1.39-1.61)$ & $<0.001$ \\
\hline Sore nipples & 61.8 & 49.8 & $1.63(1.53-1.75)$ & $<0.001$ & $1.61(1.50-1.73)$ & $<0.001$ \\
\hline Other breastfeeding problems & 63.0 & 33.6 & $3.36(3.13-3.61)$ & $<0.001$ & $3.22(3.00-3.46)$ & $<0.001$ \\
\hline Any breastfeeding problems & 63.3 & 48.6 & $1.83(1.75-1.91)$ & $<0.001$ & $1.83(1.74-1.92)$ & $<0.001$ \\
\hline
\end{tabular}

${ }^{a}$ Logistic regression adjusted for maternal age, maternal pre-pregnancy BMI, maternal education, family income, maternal smoking, fibre intake, and energy intake

complications and duration might not be causal. First, no dose-response relationship between the amount of ingested probiotics and breastfeeding complications was found. Second, probiotics consumers breastfed longer despite increased incidence of reported breastfeeding complications. As in other studies [2, 25, 26], breastfeeding complications such as mastitis were associated with precocious weaning in this study population. Third, results seem to be confounded by socioeconomic factors such as education. Educated women reported a higher probiotic milk intake and are known to breastfeed longer [27]. At the same time, educated women have higher health literacy, defined as the capacity to obtain, process, and understand basic health information and services needed to make appropriate health decisions. They are, therefore, more observant and consult the health-care system more often [28, 29]. This might partly explain the higher prevalence of reported breastfeeding problems leading to healthcare consultations among probiotic milk consumers found in this study. However, results remained significant after adjustment for socioeconomic factors, as well as in stratified analysis for education, income, and BMI (results not shown).

This epidemiologic study underlines the need to perform RCTs with defined amounts of specified probiotic strains and clinical examination of the women.

While probiotic strains studied in this cohort were La-5, Bb12, and LGG, the RCTs previously performed investigated the effect of Lactobacillus (L.) salivarius, L. gasseri, and/or L. fermentum. A recently published study showed that a daily consumption of $250 \mathrm{ml}$ product $\mathrm{A}$ as used in this study led to the presence of La-5, Bb12, and LGG in breast milk samples for only a small number of women [30]. If the positive effects of probiotics on breast health indeed should be accomplished by suggested local effects such as competitive exclusion [10], production of antimicrobials [11], normalization of breast tissue permeability [12], or increase of immunoglobulin A in breast milk epithelium [13], probiotic strains used in these commonly sold probiotic milk products might not be effective in regard to breastfeeding complications. However, another hypothesis links the risk for mastitis to the state of the host's immune system [4]. Several RCTs based on product A were performed showing that intake of $250 \mathrm{ml}$ product $\mathrm{A} /$ day during pregnancy and breastfeeding compared to a placebo fermented milk led to a higher prevalence of all three probiotic bacteria strains at 3 month postpartum in the mothers' stool samples. Their children had a higher prevalence of LGG in their stool samples at 10 days and 3 months of age [31] and lower risk for atopic dermatitis at age 2 years [32]. Another RCT showed that ingestion of $250 \mathrm{ml} /$ day of product A reduced the risk for antibiotic-associated diarrhoea [33]. Consumption of the probiotic milk consumed in this study might thus have an impact on the general immune state.

In 2008, Jiménez et al. randomized women $(n=20)$ with remaining mastitis symptoms after antibiotic treatment to intake of either L. salivarius and L. gasseri or placebo [7]. In 2010, Arroyo et al. randomized women $(n=352)$ with mastitis into three treatment groups: standard antibiotics, $L$. fermentum, or L. salivarius [6]. In both studies, the Lactobacilli groups had lower Staphylococcus counts after treatment and improved faster. Another RCT by the same group, published in 2016, evaluated a preventive effect of $L$. salivarius intake from pregnancy week 30 until delivery in women ( $n=108)$ with a history of mastitis [8]. The probiotics group had a significantly lower incidence of mastitis and lower bacterial counts if mastitis did occur. In 2017, Hurtado et al. randomized women who were given antibiotic treatment at delivery $(n=625)$ to either intake of L. fermentum or placebo for 16 weeks. Women in the probiotic group had significantly lower incidence of mastitis [9]. Furthermore, this 
study differs by evaluating dietary intake during the first half of pregnancy even if it is assumed that the reported habitual intake of probiotic milk products in pregnancy is a proxy of the continued habitual intake during breastfeeding [16, 34]. In this epidemiologic setting, the outcome variables were based on the women's self-reported data and their own initiative to use health-care services and not on medical records with International Classification of Disease (ICD) codes or examination performed by health-care professionals, which might have introduced bias as described above regarding level of education. Incidences of mastitis diagnosis and indications for antibiotic treatment differ considerably between different countries [1,35], which further impedes comparison of study results from different countries. Another RCT on 8 week prophylactic L. fermentum intake is currently performed in Australia $(n=600)$ with a reported mastitis incidence of $15-21 \%$ comparable to the incidence in this population [36].

\section{Strengths and limitations}

To the best of our knowledge, this is the first study to examine the possible effect of probiotic milk intake during pregnancy on breastfeeding complications and duration in an epidemiologic population-based setting. Strengths of this study are its size, with 57,134 women included, the comprehensive information on lifestyle and socioeconomics and the prospective design with registration of probiotic milk intake before possible breastfeeding complications might occur. The MoBa FFQ has been extensively validated [22, 37, 38]. However, several limitations need to be considered when interpreting the results. The outcome was based on the women's self-reported data referring to if and why they contacted health-care services. As discussed above, this might have introduced bias, as better educated women are known to both breastfeed longer and having a lower threshold for contacting health-care services [28]. Even if a clinical follow-up of all women would have been desirable, it is unfeasible in a population-based study like MoBa. Since exposure is self-reported in a semi-quantitative FFQ, there is no information on the exact intake of probiotic bacterial count or measurement of actual bacterial count and type in the breast milk. However, the reported median daily intake in this study is comparable to the reported intake in most of the published RCTs [6-8]. The FFQ is answered at gestational week 22 and there is no comparable information on probiotics intake after delivery. However, it can be assumed that the reported habitual intake of probiotic milk products in pregnancy is a proxy of the continued habitual intake during breastfeeding. Although pregnancy is a time when most women think a lot about healthy eating, the major changes occur for intake of alcohol and coffee, while their core diet largely remains unchanged [34]. Maternal probiotic milk intake was also asked for in a less comprehensive way in MoBa Q1 and Q3 regarding the time period from before pregnancy to answering Q3 in pregnancy week 32, showing that most women continued to consume probiotic milk products as before pregnancy [16].

Administration of antibiotics, common as prophylaxis in obstetrics, or as treatment for manifest infection, might have interfered with the probiotic effect; this type of datum is not available in the MoBa data set. However, stratifying women by vaginal delivery or delivery by caesarean section, when prophylactic antibiotics treatment is usually given, did not change the results (data not shown). Unfortunately, MoBa provides no data on the exact time when the mother attracts breastfeeding complications or stops breastfeeding. Therefore, the possibility of reverse causality explaining the results-women breastfeeding longer having more time at risk for breastfeeding complications-cannot be completely excluded. However, as the analysis was restricted to women who initiated breastfeeding as well as to breastfeeding complications reported during the first month after delivery, we judge the risk for reverse causality as very low. Women were asked what, but not how, they fed their children; whether they were breastfeeding and/or bottle-feeding pumped breast milk might have affected the risk of developing breastfeeding complications. Despite adjustment for relevant confounders, residual confounding is probably still part of this association, as discussed above.

\section{Conclusions}

Among 57,134 women from MoBa, self-reported probiotic milk intake during the first half of pregnancy was statistically associated with increased risk for self-reported breastfeeding complications, including mastitis. However, this association is probably not causal, as probiotic milk intake was also associated with longer breastfeeding duration. Further studies, specifically large RCTs with specified probiotic strains, defined exposure time, and clinical evaluation of breast complications in different populations, are needed to further investigate the association between probiotics intake and breastfeeding complications.

Acknowledgements Open access funding provided by University of Gothenburg. We are grateful to all the participating families in Norway who take part in this ongoing cohort study. The Norwegian Mother and Child Cohort Study is supported by the Norwegian Ministry of Health and Care Services and the Ministry of Education and Research, NIH/ NINDS (Grant no. 1 UO1 NS 047537-01 and grant no. 2 UO1 NS 047537-06A1). This work was supported by grants from Goljes minnesfond stiftelsen Sigurd och Elsa (LA2018-0025 "Probiotikaintag och risk för amningskomplikationer") and Wilhelm och Martina Lundgren Vetenskapsfond (nr 2018-2074 "Probiotikaintag och risk för amningskomplikationer"). The funders had no role in study design, data collection and analysis, decision to publish, or preparation of the manuscript. 


\section{Compliance with ethical standards}

Conflict of interest The authors declare that they have no conflict of interest.

Ethical standards The establishment and data collection in $\mathrm{MoBa}$ was previously based on a license from the Norwegian Data protection agency and approval from The Regional Committee for Medical Research Ethics, and it is now based on regulations related to the Norwegian Health Registry Act. The Regional Committee for Medical Research Ethics has approved the current study (2017/1820/REK sør- $\varnothing \mathrm{st} \mathrm{B})$.

Informed consent Informed consent was obtained from each MoBa participant upon recruitment.

Open Access This article is distributed under the terms of the Creative Commons Attribution 4.0 International License (http://creativeco mmons.org/licenses/by/4.0/), which permits unrestricted use, distribution, and reproduction in any medium, provided you give appropriate credit to the original author(s) and the source, provide a link to the Creative Commons license, and indicate if changes were made.

\section{References}

1. WHO (2000) Mastitis - causes and management. World Health Organization (WHO), Geneva, Switzerland.

2. Walker $\mathrm{M}$ (2008) Conquering common breast-feeding problems. J Perinat Neonatal Nurs 22(4):267-274. https://doi.org/10.1097/01. JPN.0000341356.45446.23

3. WHO (2001) The optimal duration of exclusive breastfeedingreport of an expert consultation. World Health Organization (WHO), Geneva.

4. Ingman WV, Glynn DJ, Hutchinson MR (2014) Inflammatory mediators in mastitis and lactation insufficiency. J Mammary Gland Biol Neoplasia 19(2):161-167. https://doi.org/10.1007/ s10911-014-9325-9

5. Fernandez L, Arroyo R, Espinosa I, Marin M, Jimenez E, Rodriguez JM (2014) Probiotics for human lactational mastitis. Benef Microbes 5(2):169-183. https://doi.org/10.3920/BM2013.0036

6. Arroyo R, Martin V, Maldonado A, Jimenez E, Fernandez L, Rodriguez JM (2010) Treatment of infectious mastitis during lactation: antibiotics versus oral administration of Lactobacilli isolated from breast milk. Clin Infect Dis 50(12):1551-1558. https://doi. org/10.1086/652763

7. Jimenez E, Fernandez L, Maldonado A, Martin R, Olivares M, Xaus J, Rodriguez JM (2008) Oral administration of Lactobacillus strains isolated from breast milk as an alternative for the treatment of infectious mastitis during lactation. Appl Environ Microbiol 74(15):4650-4655. https://doi.org/10.1128/AEM.02599-07

8. Fernandez L, Cardenas N, Arroyo R, Manzano S, Jimenez E, Martin V, Rodriguez JM (2016) Prevention of infectious mastitis by oral administration of Lactobacillus salivarius PS2 during late pregnancy. Clin Infect Dis 62(5):568-573. https://doi. org/10.1093/cid/civ974

9. Hurtado JA, Maldonado-Lobón JA, Paz Díaz-Ropero M, FloresRojas K, Uberos J, Leante JL, Affumicato L, Luz Couce M, Garrido JM, Olivares M, Fonollá J (2017) Oral Administration to nursing women of Lactobacillus fermentum CECT5716 Prevents lactational mastitis development: a randomized controlled trial. Breastfeed Med 12(4):202-209. https://doi.org/10.1089/ bfm.2016.0173
10. Beasley SS, Saris PE (2004) Nisin-producing Lactococcus lactis strains isolated from human milk. Appl Environ Microbiol 70(8):5051-5053. https://doi.org/10.1128/ AEM.70.8.5051-5053.2004

11. Olivares M, Diaz-Ropero MP, Martin R, Rodriguez JM, Xaus J (2006) Antimicrobial potential of four Lactobacillus strains isolated from breast milk. J Appl Microbiol 101(1):72-79. https:// doi.org/10.1111/j.1365-2672.2006.02981.x

12. Vazquez-Fresno R, Llorach R, Marinic J, Tulipani S, Garcia-Aloy M, Espinosa-Martos I, Jimenez E, Rodriguez JM, Andres-Lacueva C (2014) Urinary metabolomic fingerprinting after consumption of a probiotic strain in women with mastitis. Pharmacol Res 87:160-165. https://doi.org/10.1016/j.phrs.2014.05.010

13. Nikniaz L, Ostadrahimi A, Mahdavi R, Hejazi MA, Salekdeh GH (2013) Effects of synbiotic supplementation on breast milk levels of IgA, TGF-beta1, and TGF-beta2. J Hum Lact 29(4):591-596. https://doi.org/10.1177/0890334413490833

14. Myhre R, Brantsaeter AL, Myking S, Gjessing HK, Sengpiel V, Meltzer HM, Haugen M, Jacobsson B (2011) Intake of probiotic food and risk of spontaneous preterm delivery. Am J Clin Nutr 93(1):151-157. https://doi.org/10.3945/ajcn.110.004085

15. Brantsaeter AL, Myhre R, Haugen M, Myking S, Sengpiel V, Magnus P, Jacobsson B, Meltzer HM (2011) Intake of probiotic food and risk of preeclampsia in primiparous women: the Norwegian Mother and Child Cohort Study. Am J Epidemiol 174(7):807-815. https://doi.org/10.1093/aje/kwr168

16. Nordqvist M, Jacobsson B, Brantsaeter AL, Myhre R, Nilsson S, Sengpiel V (2018) Timing of probiotic milk consumption during pregnancy and effects on the incidence of preeclampsia and preterm delivery: a prospective observational cohort study in Norway. BMJ Open 8(1):e018021. https://doi.org/10.1136/bmjopen-2017018021

17. Magnus P, Irgens LM, Haug K, Nystad W, Skjaerven R, Stoltenberg C, MoBa Study G (2006) Cohort profile: the Norwegian mother and child cohort study (MoBa). Int J Epidemiol 35(5):1146-1150. https://doi.org/10.1093/ije/dyl170

18. Irgens LM (2000) The Medical Birth Registry of Norway: epidemiological research and surveillance throughout 30 years. Acta Obstet Gynecol Scand 79(6):435-439

19. Norwegian Institute of Public Health (2018) Official homepage of the Norwegian Mother and Child Cohort Study (MoBa). https ://www.fhi.no/en/studies/moba/. Accessed 19 Dec 2018

20. Lauritzen J (2018) FoodCalc. https://www.ibt.ku.dk/jesper/FoodC alc/Default.htm. Accessed 19 Dec 2018

21. Mattilsynet (2018) Matvaretabellen (The Norwegian Food Composition Table). https://www.matvaretabellen.no/. Accessed 18 Dec 2018

22. Brantsaeter AL, Haugen M, Alexander J, Meltzer HM (2008) Validity of a new food frequency questionnaire for pregnant women in the Norwegian mother and child cohort study (MoBa). Matern Child Nutr 4(1):28-43. https://doi.org/10.111 1/j.1740-8709.2007.00103.x

23. WHO (2008) Indicators for assessing infant and young child feeding practices, Part 1 Definitions. World Health Organization (WHO), Washington DC

24. Marsál K, Persson PH, Larsen T, Lilja H, Selbing A, Sultan B (1996) Intrauterine growth curves based on ultrasonically estimated foetal weights. Acta Paediatr 85(7):843-848

25. Fetherston C (1997) Characteristics of lactation mastitis in a Western Australian cohort. Breastfeed Rev 5(2):5-11

26. Schwartz K, D'Arcy HJ, Gillespie B, Bobo J, Longeway M, Foxman B (2002) Factors associated with weaning in the first 3 months postpartum. J Fam Pract 51(5):439-444

27. Kristiansen AL, Lande B, Overby NC, Andersen LF (2010) Factors associated with exclusive breast-feeding and breast-feeding 
in Norway. Public Health Nutr 13(12):2087-2096. https://doi. org/10.1017/S1368980010002156

28. Berkman ND, Sheridan SL, Donahue KE, Halpern DJ, Crotty K (2011) Low health literacy and health outcomes: an updated systematic review. Ann Intern Med 155(2):97-107. https://doi. org/10.7326/0003-4819-155-2-201107190-00005

29. Crozier SR, Robinson SM, Borland SE, Godfrey KM, Cooper C, Inskip HM, Group SWSS (2009) Do women change their health behaviours in pregnancy? Findings from the Southampton Women's Survey. Paediatr Perinat Epidemiol 23(5):446-453. https:// doi.org/10.1111/j.1365-3016.2009.01036.x

30. Simpson MR, Avershina E, Storro O, Johnsen R, Rudi K, Oien T (2018) Breastfeeding-associated microbiota in human milk following supplementation with Lactobacillus rhamnosus GG, Lactobacillus acidophilus La-5, and Bifidobacterium animalis ssp. lactis Bb-12. J Dairy Sci 101(2):889-899. https://doi.org/10.3168/ jds.2017-13411

31. Dotterud CK, Avershina E, Sekelja M, Simpson MR, Rudi K, Storro O, Johnsen R, Oien T (2015) Does maternal perinatal probiotic supplementation alter the intestinal microbiota of mother and child? J Pediatr Gastroenterol Nutr 61(2):200-207. https:// doi.org/10.1097/MPG.0000000000000781

32. Dotterud CK, Storro O, Johnsen R, Oien T (2010) Probiotics in pregnant women to prevent allergic disease: a randomized, double-blind trial. Br J Dermatol 163(3):616-623. https://doi.org/10 $.1111 /$ j.1365-2133.2010.09889.x

33. Wenus C, Goll R, Loken EB, Biong AS, Halvorsen DS, Florholmen J (2008) Prevention of antibiotic-associated diarrhoea by a fermented probiotic milk drink. Eur J Clin Nutr 62(2):299-301. https://doi.org/10.1038/sj.ejcn.1602718

34. Crozier SR, Robinson SM, Godfrey KM, Cooper C, Inskip HM (2009) Women's dietary patterns change little from before to during pregnancy. J Nutr 139(10):1956-1963. https://doi. org/10.3945/jn.109.109579

35. Kvist LJ (2013) Re-examination of old truths: replication of a study to measure the incidence of lactational mastitis in breastfeeding women. Int Breastfeed J 8(1):2. https://doi. org/10.1186/1746-4358-8-2

36. Bond DM, Morris JM, Nassar N (2017) Study protocol: evaluation of the probiotic Lactobacillus Fermentum CECT5716 for the prevention of mastitis in breastfeeding women: a randomised controlled trial. BMC Pregnancy Childbirth 17(1):148. https://doi. org/10.1186/s12884-017-1330-8

37. Brantsaeter AL, Haugen M, Julshamn K, Alexander J, Meltzer HM (2009) Evaluation of urinary iodine excretion as a biomarker for intake of milk and dairy products in pregnant women in the Norwegian Mother and Child Cohort Study (MoBa). Eur J Clin Nutr 63(3):347-354. https://doi.org/10.1038/sj.ejcn.1602952

38. Brantsaeter AL, Haugen M, Rasmussen SE, Alexander J, Samuelsen SO, Meltzer HM (2007) Urine flavonoids and plasma carotenoids in the validation of fruit, vegetable and tea intake during pregnancy in the Norwegian Mother and Child Cohort Study (MoBa). Public Health Nutr 10(8):838-847. https://doi. org/10.1017/S1368980007339037 